\title{
Experiencias en zoocría de lapa (Cuniculus paca) como aporte a su conservación y aprovechamiento sostenible en el departamento del Meta
}

\section{Experiences in animal breeding of Cuniculus paca as a contribution to their conservation and sustainable use in Meta Department}

\author{
Rincón Mosso Freddy Yesid ${ }^{1}$, Tinjacá León Jennifer Katherine ${ }^{1}$ y \\ Murillo Pacheco Ricardo² \\ ${ }^{1}$ Licenciado en Producción Agropecuaria. Universidad de los Llanos y \\ ${ }^{2}$ Medico Veterinario Zootecnista. Docente Universidad de los Llanos \\ freddyrinconm@yahoo.es
}

Recibido 05 de Marzo 2013, Aceptado 15 de Abril 2013

\section{RESUMEN}

La lapa (Cuniculus paca) es una de las especies que ha sido más utilizada en Colombia a lo largo de su historia, porque tiene una gran adaptación a condiciones adversas, manteniendo una buena producción de carne. Debido a la disminución de algunos núcleos poblacionales de lapa y el aumento de las poblaciones sometidas al encierro, se planteó generar información del comportamiento de la especie a partir de los individuos cautivos, de manera que fueron realizadas diferentes practicas alternativas de uso y manejo, como aporte a la conservación de la especie, con el fin de generar beneficios socioeconómicos, aprovechando las características de la lapa. A partir de la visita a cuatro núcleos de reubicación y el parque Ecozoo Merecure durante dos meses de seguimiento, se obtuvo información acerca de la biología reproductiva de la especie, características de la población en cautiverio y manejo ex situ realizado. Esta información acerca de la especie y su hábitat en cautiverio fue utilizada para plantear diferentes alternativas de manejo y uso de la especie. Para involucrar todos los componentes en la práctica de crianza de la fauna silvestre, obteniendo una aproximación a la percepción de las personas hacia estas alternativas de uso. Por tal motivo se generó un manual sobre la zoocría de lapa. La población en cautiverio muestra un predominio de la edad adulta debido a que su índice de mortalidad es bajo. Las hembras presentan su primer estro a los seis meses de edad, el promedio de 
gestación obtenido es de 116 días, aunque es menor en comparación con otras poblaciones, implica un lento crecimiento. Por otro lado, se presenta una tendencia a la estacionalidad en los procesos reproductivos, aunque las hembras en su mayoría alcanzarían a tener dos partos por año, pero esto no se logra porque los individuos en cautiverio no son aptos para programas de reintroducción, por lo tanto, es necesario plantear programas de reproducción de lapa en cautiverio marcando los individuos para realizar un adecuado seguimiento. También se analizaron las alternativas de uso como: ecoturismo, exhibición en parques zoológicos, zoocría para la producción de carne, y se llegó a la conclusión que es importante promover el uso sostenible de la lapa teniendo en cuenta sus características favorables para una zoocría productiva.

Palabras clave: Cuniculus paca, cautiverio, zoocría, fauna silvestre.

\section{ABSTRACT}

The Cuniculus paca is a species that has been most widely used in Colombia along its history, because it has a great adaptation to adverse conditions, maintaining good meat production. Due to decreased some population barnacle and increasing populations subjected to confinement, the researchers have raised to generate information about behavior of the species from captive individuals, so they were made different use and rearing practices alternatives as input the conservation of the species, in order to generate economic benefits, taking advantage of the characteristics of $C$. paca. From the visit to four cores relocation and Merecure Ecozoo Park for two months, the researchers obtained information about the reproductive biology of this specie, characteristics of the captive population and ex situ rearing. This information about their habitat and in captivity was used to propose different alternatives handling and use. To involve all components rearing practices of wildlife, obtaining an approximation to the perception of people about of these alternatives of use. For this reason, we created a manual on animal breeding of $C$. paca. The captive population is predominantly young adulthood, because their mortality rate is low. Females have their first estrus after six months old of age; the average obtained is 116 gestation days although it 
is low in comparison to other populations implies a slow growth. Furthermore, there is a tendency to seasonality in the reproductive process, while females reach mostly have two deliveries per year, but this fails because captive individuals are not suitable for reintroduction of wildlife species programs, so Therefore, it is necessary to raise $C$. paca breeding programs in captivity marking individuals for a proper follow-up. Also analyzed using alternatives such as ecotourism, exhibition in zoos, animal breeding for meat production, and the researchers conclude that it is important to promote the sustainable use of $C$. paca considering its favorable characteristics for a productive animal breeding.

Keywords: Cuniculus paca, captivity, animal breeding, wildlife.

\section{INTRODUCCIÓN}

La biología de la conservación es el estudio científico de la biodiversidad y su manejo para generar beneficio humano sostenible. Es una ciencia interdisciplinaria, que busca preservar la biodiversidad, estudiando su interacción con el ser humano (Cox, 1997). Existen dos modalidades de conservación, in situ y ex situ, cuando se tiene en cuenta si el organismo se encuentra en su hábitat ó fuera de éste, respectivamente. La conservación ex situ es una valiosa herramienta para el desarrollo de programas de manejo y conservación in situ, teniendo en cuenta la información que se puede obtener acerca de la biología de las especies de fauna en estas condiciones.

Uno de los principios básicos de la conservación de la fauna es la disponibilidad de alimento natural y abrigo para las poblaciones de cada una de las especies de un hábitat dado. Dos importantes amenazas a las que se enfrenta la vida silvestre es la destrucción de hábitats, debido a la contaminación, a la agricultura y sobre todo, a la expansión urbana; la otra amenaza es la fragmentación de corredores biológicos en parcelas demasiado pequeñas para que puedan mantener las poblaciones autóctonas de animales (UICN, 2003).

La paca común, guagua o lapa (Cuniculus paca) es una especie de roedor que vive en las proximidades de los cursos de agua de los bosques tropicales, desde 
México hasta Paraguay y norte de Argentina, a menos de 2.000 m.s.n.m. La paca es objeto de caza por su excelente carne. La cacería indiscriminada y aún más la destrucción de su hábitat amenazan su supervivencia como especie. Actualmente las concentraciones silvestres de lapa, debido a sus características, han generado dos problemas principales para el manejo y conservación de fauna silvestre, la disminución de algunos núcleos poblacionales y el aumento de las poblaciones en cautiverio (Queriolo et al., 2008).

Uno de los objetivos de la conservación ex situ es generar información para contribuir a la conservación y manejo de la especie silvestre en cautiverio. Este trabajo expone la información de manejo obtenida de algunos individuos encontrados en cautiverio en Meta, Colombia, Parque Ecozoo Merecure, y los núcleos de Reubicación el Tesoro, la Esperanza, la Cosmopolitana y el Turpial, con lo cual se espera contribuir en la ampliación del conocimiento de la especie, para lograr el manejo sostenible de la misma como herramienta para su conservación y disminuir los efectos negativos sobre la especie.

\section{METODOLOGÍA}

Este trabajo se realizó en Villavicencio, Restrepo y Acacias, región de piedemonte llanero del Meta, con un rango de temperatura 19-34 grados centígrados, altitud de 465 metros sobre el nivel del mar, y una precipitación anual entre 1.900 y 2.300 milímetros.

Se hicieron visitas técnicas para recolectar y analizar la información sobre la lapa (Cuniculus paca) a un total de cuatro núcleos de reubicación (NR): NR "El Tesoro" (NRT), NR "El Turpial" (NRTu) NR "La Esperanza" (NRE), y NR "La Cosmopolitana" (NRC), y el parque "Ecozoo Merecure" (PEM), se hizo una revisión histórica de cada uno de los predios mencionados, realizando una investigación descriptiva iniciando un diagnóstico preliminar para determinar la población en cautiverio con el objetivo de llegar a conocer: 1. Anatomía, conformación interna y externa de la lapa. 2. Biología reproductiva. 3. Evaluación de los encierros de los núcleos de reubicación. 4. Análisis del encierro ex situ. 5. 
Análisis de los núcleos de reubicación. 6. Identificación y alimentación. 7. Manejo veterinario. 8. Reintroducción. 9. Recomendaciones para los encierros y manejo de individuos.

Toda esta investigación se realizó a través de la descripción exacta de las actividades, objetos, procesos y personas, por medio del dialogo de saberes y conocimiento empírico, relacionado con la crianza y manejo de la lapa.

\section{DIAGNÓSTICO PRELIMINAR}

Se realizaron visitas a los cinco predios para observar en qué estado y áreas estaban las lapas en cautiverio e identificar el propósito de uso de cada sitio. La información recolectada inicialmente, se presenta en las Tablas 1 y 2; del total de la población 50 individuos se manipularon 48, se observa, un porcentaje de mortalidad del $20 \%$ en los cinco predios visitados. De 48 individuos analizados 33 son hembras lo que en porcentaje sería el 68.75 y 15 son machos o sea $31.25 \%$, lo que indica una proporción de género de 2.2 hembras por macho. Sin embargo, la proporción actual de género varía con frecuencia en cada uno de los predios, debido a los nacimientos, muertes y otros factores. En general, en la mayoría de los NR y del parque Ecozoo Merecure se encontraron más hembras que machos, ya sea por causa natural o por manejo reproductivo.

Con relación a la procedencia de los animales, la mayoría provienen de los llanos orientales y son entregados por CORMACARENA, lo cual indica que existe un porcentaje alto de tráfico ilegal de esta especie; que no hay sensibilización por parte de las personas en la conservación de la fauna y que la legislación colombiana es muy flexible en estos delitos.

De acuerdo a los datos de edad de la población, la mayoría de los animales están en la edad adulta, un 60\% tienen como mínimo cinco años, de los 50 individuos contabilizados en los tres predios. Así mismo, se observa una mayor cantidad de hembras en edad adulta y muy pocas en la edad sub-adulta y juvenil, haciendo un estimativo con las personas que están a cargo se presume que del $100 \%$ de las 
hembras el $80 \%$ son adultas y el $20 \%$ restante se reparte entre juveniles y neonatos.

Tabla 1. Datos preliminares de cada predio visitado

\begin{tabular}{|c|c|c|c|c|c|}
\hline \multicolumn{6}{|c|}{ PREDIOS } \\
\hline Predio & NRT & NLE & NRTu & NRC & PEM \\
\hline Propietario & María I. Pacheco & Humberto Téllez & $\begin{array}{l}\text { Tesoro } \\
\text { Gómez }\end{array}$ & $\begin{array}{l}\text { Roberto } \\
\text { Rodríguez }\end{array}$ & Wilson Barrera \\
\hline $\begin{array}{c}\text { Edad } \\
\text { promedio de } \\
\text { las lapas }\end{array}$ & 6 meses & 10 años & 5 años & 10 años & 1 año \\
\hline $\begin{array}{l}\text { Área de los } \\
\text { encierros }\end{array}$ & $12 \mathrm{~m}^{2}$ & $14.5 \mathrm{~m}^{2}$ & $13 m^{2}$ & $\begin{array}{l}* 15 \mathrm{~m}^{2} \\
* 11.8 \mathrm{~m}^{2}\end{array}$ & 2 Has. \\
\hline $\begin{array}{l}\text { Énfasis de la } \\
\text { colección }\end{array}$ & Repoblamiento & $\begin{array}{c}\text { Repoblamiento y } \\
\text { educativo }\end{array}$ & Turístico & $\begin{array}{c}\text { Turístico, } \\
\text { educativo y } \\
\text { comercial }\end{array}$ & $\begin{array}{l}\text { Eco - turismo } \\
600 \text { Has }\end{array}$ \\
\hline Personal & $\begin{array}{c}\text { MVZ (1) } \\
\text { cuidadores (2) }\end{array}$ & $\begin{array}{c}\text { Cuidador (2) Mvz } \\
\text { (1) }\end{array}$ & $\begin{array}{l}\text { Cuidador } \\
\text { (1) MVZ } \\
\text { (1) }\end{array}$ & $\begin{array}{c}\text { Cuidador } \\
\text { (1) } \\
\text { Tecnólogo } \\
\text { (1) }\end{array}$ & $\begin{array}{c}\text { Zootecnista (1) } \\
\text { LPA (1) } \\
\text { MVZ. (1) } \\
\text { Cuidadores (2) }\end{array}$ \\
\hline
\end{tabular}

Tabla 2. Número de individuos por cada establecimiento

\begin{tabular}{ccccc}
\hline Predio & Total & Muertos & Vivos & Mortalidad (\%) \\
\hline NRT & 5 & 2 & 3 & $\mathbf{4 0}$ \\
NRTu & 4 & 0 & 4 & $\mathbf{0}$ \\
NLE & 11 & 1 & 10 & $\mathbf{9 . 1}$ \\
NRC & 15 & 7 & 8 & $\mathbf{4 6 . 6}$ \\
PEM & 15 & 0 & 15 & $\mathbf{0}$ \\
TOTAL & 50 & 10 & 40 & $\mathbf{2 0}$ \\
\hline
\end{tabular}

\section{Resultados de dos meses de seguimiento}

La natalidad no se pudo precisar con exactitud pues lamentablemente la mayoría de los predios no contaban con registros, de tal modo que los productores hicieron un estimativo, el NR la Esperanza posee el mayor índice de natalidad, el dueño alude que este parámetro está influenciado por el manejo, lo que se pudo constatar es que siempre nace una cría y que la posibilidad de que nazcan 2 es nula, hasta la fecha. 


\section{ANATOMÍA: CONFORMACIÓN INTERNA Y EXTERNA LAPA}

Para trabajar con una especie nueva en la zootecnia, es necesario conocer la anatomía básica normal y la conformación externa e interna de los individuos. Para realizar los estudios anatómicos se aprovecharon los individuos que morían por causa natural, durante el tiempo de la recolección de la información. Se observó, que el cráneo de la lapa en comparación a otros animales es diferente, es por eso que se requiere identificar algunas partes morfológicas. En las Figuras 1, 2 y 3 se ubican los nombres de algunos huesos del cráneo. En la Figura 4 se observan los órganos internos de la especie.

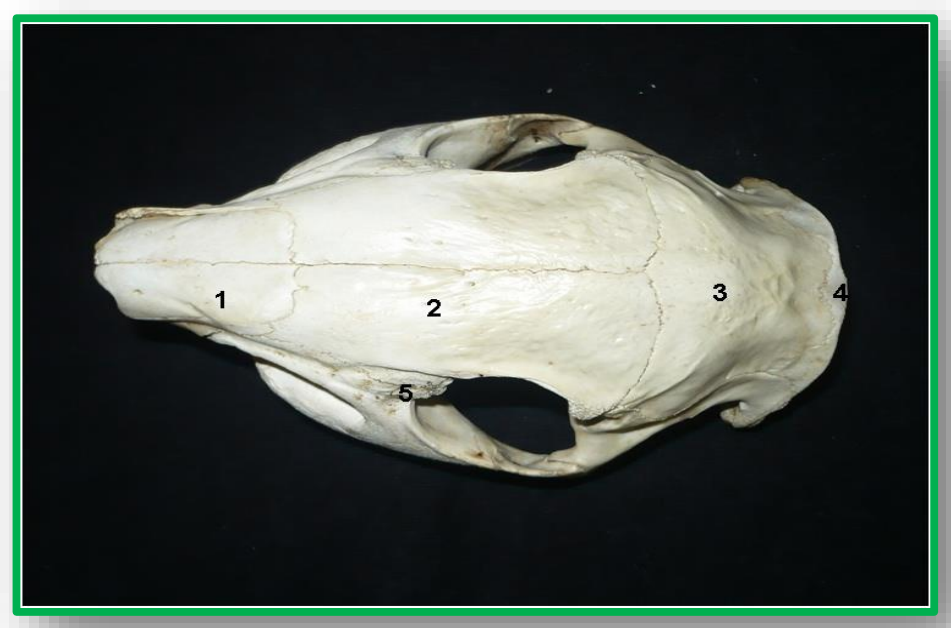

Figura 1. Huesos del cráneo - vista dorsal:

1: Nasal.

2: Frontal.

3: Parietal.

4: Occipital.

5: Lagrimal.

Fotografía Rincón, 2007

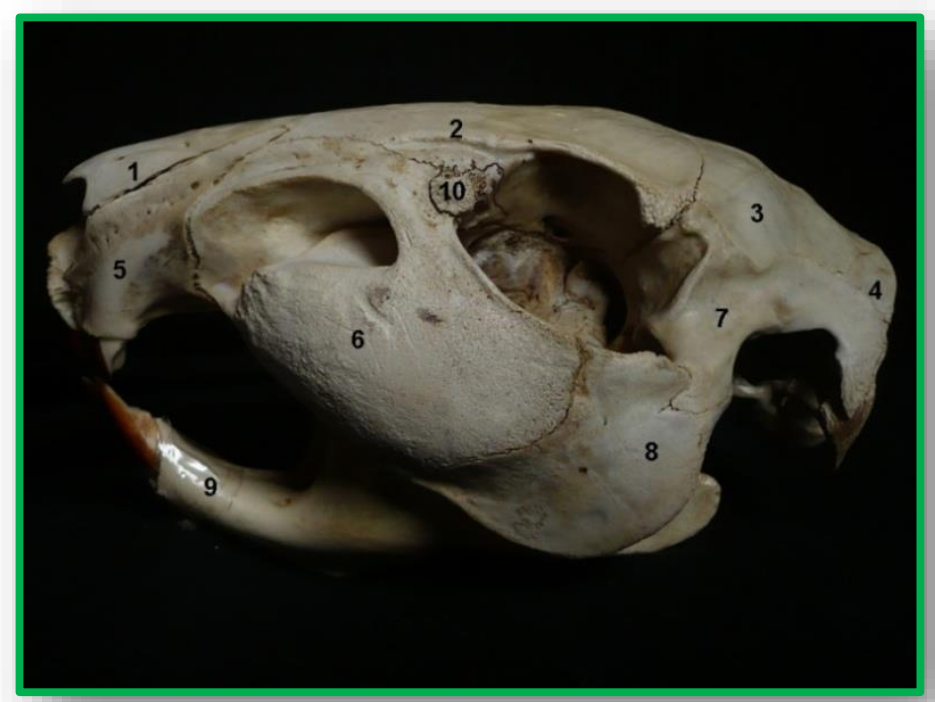

Figura 2. Huesos del cráneo - vista lateral

1: Nasal.

2: Frontal.

3: Parietal.

4: Occipital.

5: Premaxilar.

6: Maxilar.

7: Temporal.

8: Malar.

9: Mandíbula.

10: Lagrimal.

Fotografía Rincón, 2007 


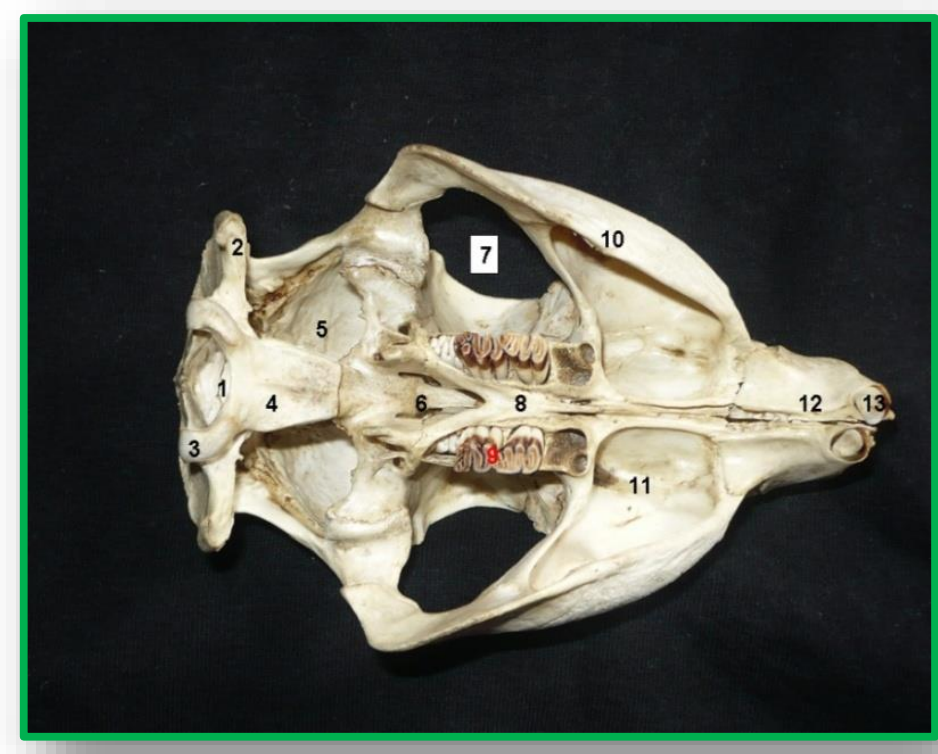

Figura 3. Huesos del

Cráneo - vista ventral:

1: Agujero magno.

2: Apófisis paramastoides.

3: Cóndilos occipitales.

4: Porción basilar del occipital.

5: Agujero donde se sitúa la ampolla timpánica.

6: Orificios nasales posteriores.

7: Porción orbitaria. 8: Palatino.

9: Molares.

10: Maxilar.

11: Seno maxilar.

12: Premaximar,

13: Incisivos.

Fotografía: Tinjacá, (2007)

Al realizar la disección de las partes internas (Figura 4) se observa los siguientes órganos:

Corazón. Es normal con relación a su cuerpo, es de una forma cónica, el espacio en que se encuentra los pulmones y el corazón no es tan amplio. Es de color rojizo oscuro, puede medir aproximadamente $5 \mathrm{~cm}$ de largo y pesar en promedio $55 \mathrm{~g}$ en animales adultos (Tabla 3 ).

Pulmones. Mientras que el pulmón derecho tiene tres lóbulos, el izquierdo sólo tiene dos, con un hueco para acomodar el corazón. Son de color rojizo oscuro, puede medir aproximadamente $8 \mathrm{~cm}$ y pesar en promedio $44 \mathrm{~g}$ en animales adultos (Tabla 3).

Hígado. Pesa aproximadamente $216 \mathrm{~g}$ es de color rojo oscuro y está situado en el cuadrante superior derecho de la cavidad abdominal, la vesícula biliar es ovalada, de color amarillo rojizo y de largo llega a medir hasta $5 \mathrm{~cm}$ (Tabla 3).

Riñones. Son pequeños en forma de fríjol, son de color rojizo oscuro y en un adulto pueden llegar a pesar aproximadamente $15 \mathrm{~g}$ y medir $6 \mathrm{~cm}$ de largo (Tabla $3)$. 


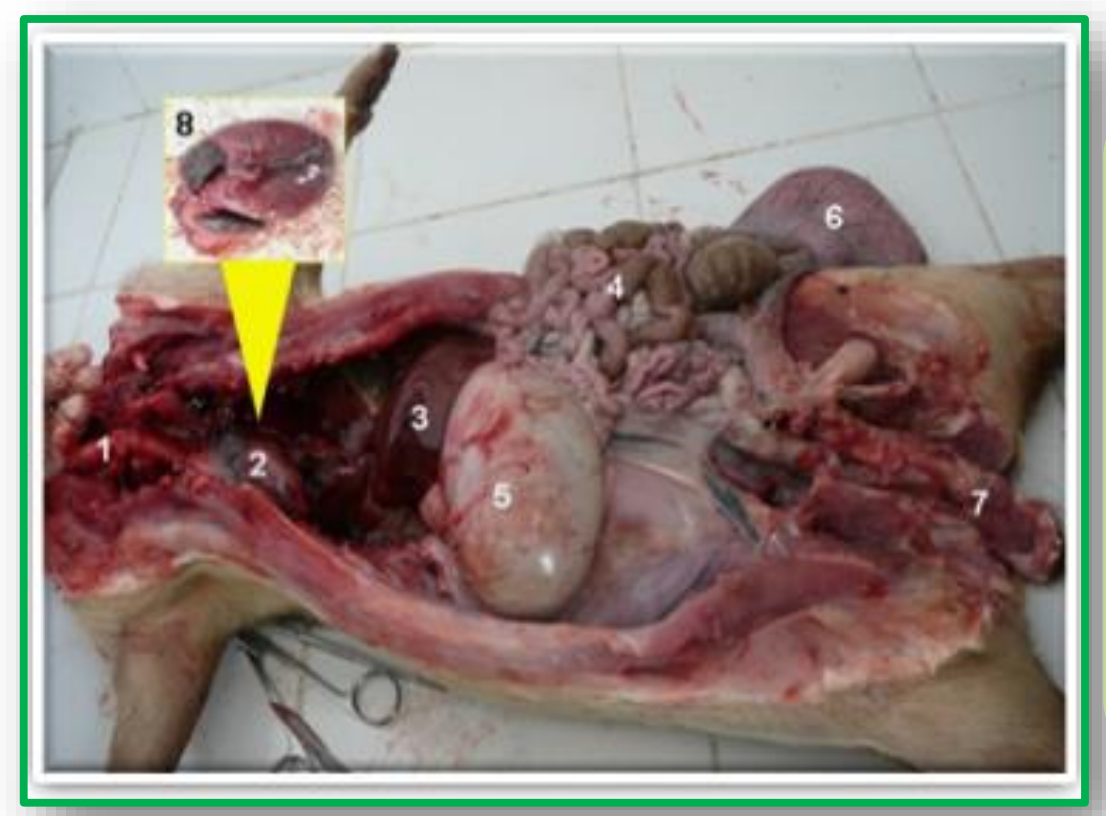

Figura 4. Órganos internos de la Lapa:

1: Tráquea.

2: Pulmones.

3: Hígado.

4: Intestinos.

5: Estómago.

6: Útero.

7: Recto.

8: Corazón.

Fotografía Tinjacá, (2007)

Tabla 3. Promedios de peso y longitud de los órganos internos de una Lapa adulta.

\begin{tabular}{|c|c|c|c|c|}
\hline Órgano & Peso (kg) & $\begin{array}{l}\text { Longitud } \\
\text { (cm) }\end{array}$ & $\begin{array}{c}\text { Rango peso } \\
\text { (kg). }\end{array}$ & $\begin{array}{l}\text { Rango longitud } \\
\text { (cm) }\end{array}$ \\
\hline Riñón & 0.0318 & 6 & $0.015-0.045$ & 6 \\
\hline Corazón & 0.044 & 7 & $0.025-0.055$ & 7 \\
\hline $\begin{array}{l}\text { Pulmón } \\
\text { Tráquea pulmón }\end{array}$ & 0.044 & & $0.033-0.085$ & \\
\hline Hígado & 0.216 & 18 & $0.175-0.250$ & $16-20$ \\
\hline $\begin{array}{l}\text { Bazo* } \\
\text { Páncreas** }\end{array}$ & 0.019 & $\begin{array}{l}{ }^{*} 5.12 \\
* * 11.5\end{array}$ & $0.005-0.025$ & $\begin{array}{c}{ }^{*} 3-6 \\
* * 10-13\end{array}$ \\
\hline Intestinos & 0.479 & 742 & $0.380-0.610$ & $700-770$ \\
\hline Ciego & & 42.75 & & \\
\hline Intestino grueso & & 356 & & \\
\hline Intestino delgado & & 349 & & \\
\hline Estómago & 0.198 & 15.5 & $0.120-0.245$ & $42-46$ \\
\hline $\begin{array}{l}\text { Sistema } \\
\text { reproductor } \\
\text { hembra }\end{array}$ & 0.133 & 25.5 & $0.035-0.075$ & $26-36$ \\
\hline Canal & 5.829 & & $5.5-6.785$ & \\
\hline En pie & 8.2 & & $6.5-9.5$ & \\
\hline
\end{tabular}

Fuente: El estudio, muestra 7 animales. 
Estomago. A lo largo puede medir hasta $15.5 \mathrm{~cm}$ y con alimento adentro puede pesar aproximadamente $200 \mathrm{~g}$. Es de color blanco amarillento y tiene una forma semi-ovalada (Tabla 3).

Intestinos. La longitud total del intestino en animales adultos es en promedio de $7.42 \mathrm{~m}$ y pude pesar aproximadamente $479 \mathrm{~g}$. El intestino de las hembras es más largo que el de los machos (Tabla 3).

El rendimiento en canal de una lapa adulta de $8.2 \mathrm{~kg}$ es del $71 \%$, que traducido en peso es de aproximadamente de $5.829 \mathrm{~kg}$ (Tabla 3).

\section{BIOLOGÍA REPRODUCTIVA}

Machos. Según la información recolectada en los establecimientos visitados, sobre la reproducción en lapas, los machos llegan a su madurez sexual a los tres meses de edad, con un peso aproximado de 3 a $4 \mathrm{~kg}$, de los animales muestreados se pudieron recoger los siguientes resultados:

En un macho adulto el pene tiene una longitud promedio de $8.1 \mathrm{~cm}$ (Figura 5) aunque éste depende del estado de desarrollo de los animales, presenta tres clases de espículos de tamaños ascendentes, contra la dirección de la salida del miembro, una con forma de anzuelo, las cuales producen lesiones en el epitelio vaginal, dando origen a pequeñas hemorragias que probablemente producen un coágulo que actúa como tapón vaginal, el cual impide que el semen se derrame; las segundas de tipo fungiforme y pequeñas están dispersas por toda la superficie anterior; el tercer tipo corresponde a dos estructuras corneas de $1 \mathrm{~cm}$ de longitud y 1 milímetro de diámetro; éstas espinas están ubicadas en la punta, son retráctiles y quizá su función se relacione con la estimulación del aparato genital para facilitar la nidación del embrión (Castro, 1996). El glande es de consistencia blanda y suave en la punta, con un orificio uretral externo o meato urinario de 4 mm aproximadamente.

Generalmente el macho solo puede montar a la hembra de la lapa una vez, pues como se mencionó anteriormente los espículos (Figura 5) van en dirección 
contraria, cuando el pene sale de la vagina lastima a la hembra, por tal motivo la hembra empieza a evadir el macho dando como resultado agresiones entre ellos que en algunos casos puede tener graves consecuencias.

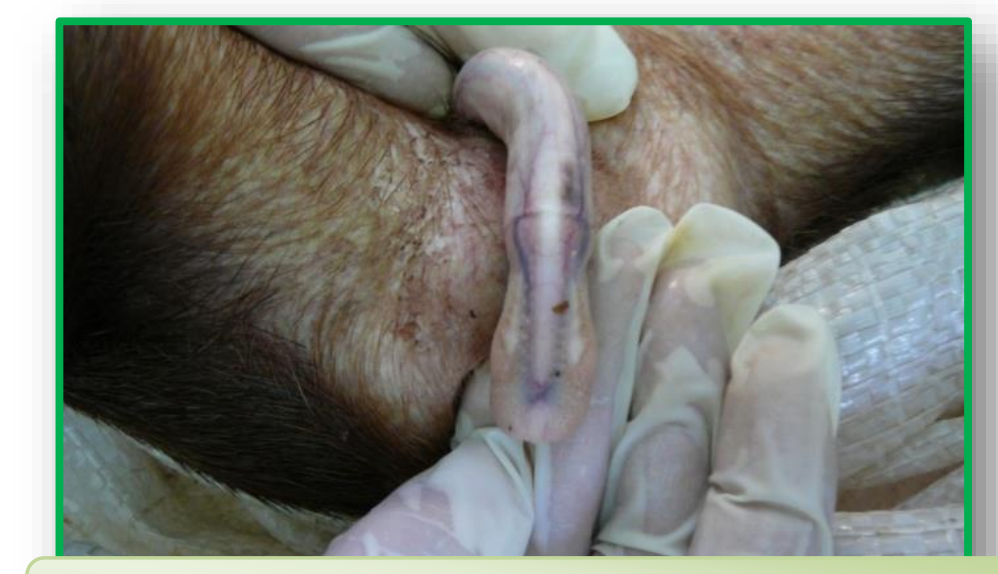

Figura 5. Pene de un macho de lapa adulto Fotografía: Tinjacá, (2007)

Hembras. Las hembras presentan la vulva con un tamaño aproximado de $2.5 \mathrm{~cm}$. de consistencia blanda, con un mechón de pelo alrededor, lo cual posiblemente tiene la función de esparcir la orina en el momento de marcar su territorio, seguida se encuentra la vagina que mide aproximadamente $6 \mathrm{~cm}$ posteriormente el cervix de consistencia dura, luego se encuentra el útero con una medida aproximada de $5 \mathrm{~cm}$. de consistencia blanda, con forma cilíndrica, después están las astas 0 cuernos uterinos con una medida aproximada de $13 \mathrm{~cm}$ y por último los ovarios, en forma de óvalos, de color amarillento (Figura 6).

Épocas de nacimiento. En la Tabla 3 se puede observar la información del ciclo reproductivo de hembras obtenidas a través de entrevistas realizadas a los cuidadores.

Según la información recolectada en los predios visitados, sobre la reproducción en lapas, los machos llegan a su madurez sexual a los tres meses de edad, lo que indica que se empiezan a reproducir en muy poco tiempo lo cual es importante al momento de iniciar una explotación de zoocría. La desventaja es que la hembra 
solo se deja montar una vez, a lo máximo dos veces, pues es bastante dolorosa la copula para ella, por los espículos (no se identificó con exactitud cuál es su función) que el macho presenta en el pene.

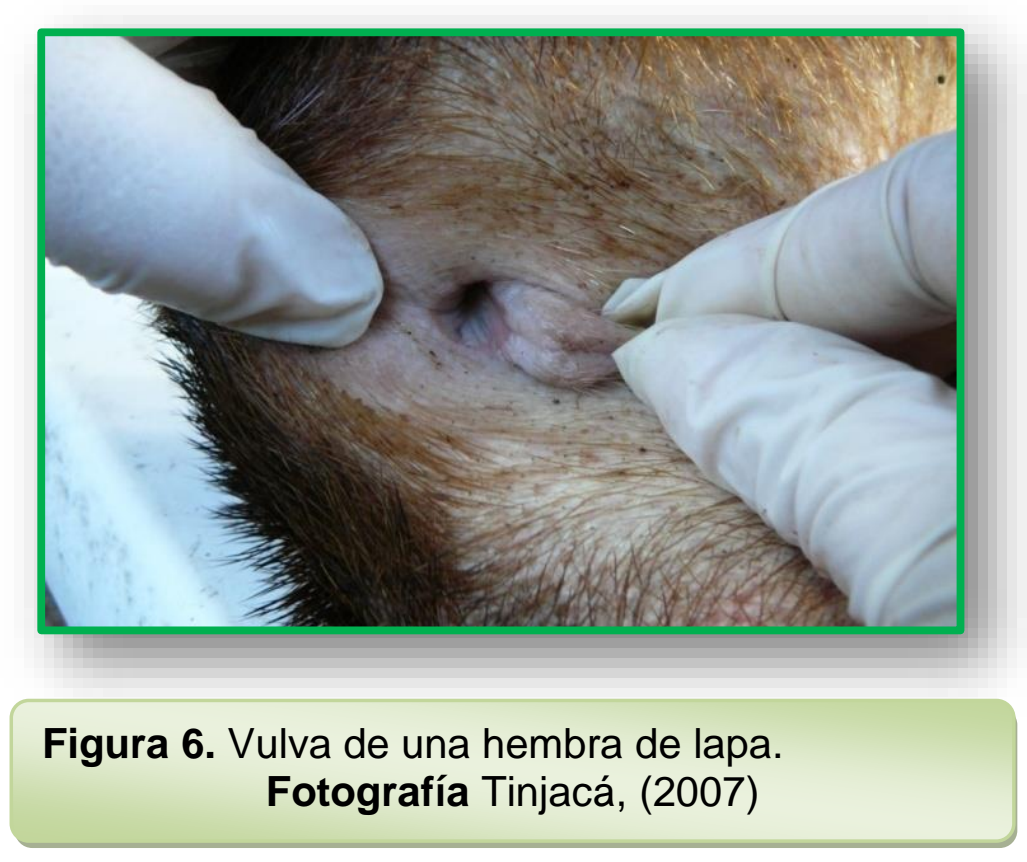

Tabla 3. Ciclo reproductivo de hembras de lapa

\begin{tabular}{|c|c|c|c|c|c|c|}
\hline Predios & $\begin{array}{l}\text { Crías } \\
\text { por } \\
\text { parto }\end{array}$ & $\begin{array}{c}\text { Partos } \\
\text { por } \\
\text { años }\end{array}$ & $\begin{array}{l}\text { Época } \\
\text { De } \\
\text { Partos }\end{array}$ & Gestación & $\begin{array}{l}\text { Destete de } \\
\text { Crías }\end{array}$ & $\begin{array}{c}\text { Crías } \\
\text { comiendo } \\
\text { alimento } \\
\text { sólido } \\
\end{array}$ \\
\hline NRT & 1 & 1 & Dic - Ene & $\begin{array}{l}114-116 \\
\text { días }\end{array}$ & $\begin{array}{l}\text { Entre segunda y } \\
\text { tercera sem. }\end{array}$ & $\begin{array}{l}\text { Primera } \\
\text { semana }\end{array}$ \\
\hline NRTu & $\mathrm{Nr}$ & $\mathrm{Nr}$ & Dic - Ene & $\mathrm{Nr}$ & $\mathrm{Nr}$ & $\mathrm{Nr}$ \\
\hline NRE & 1 & 1 & $\begin{array}{l}\text { May - jun } \\
\text { Dic - ene }\end{array}$ & $\begin{array}{l}115-117 \\
\text { días }\end{array}$ & $\begin{array}{l}\text { Al mes de } \\
\text { nacidos }\end{array}$ & $\begin{array}{l}\text { Primera } \\
\text { semana }\end{array}$ \\
\hline NRC & 1 & 1 & $\begin{array}{l}\text { May - Jun } \\
\text { Diciembre }\end{array}$ & $\mathrm{Nr}$ & $\begin{array}{l}\text { Al mes de } \\
\text { nacidos }\end{array}$ & $\mathrm{Nr}$ \\
\hline PEM & 1 & 2 & May -Jun & $\begin{array}{l}114 \text { días } \\
\text { aprox. }\end{array}$ & $\begin{array}{l}\text { Al mes de } \\
\text { nacidos }\end{array}$ & $\begin{array}{l}\text { Primera } \\
\text { semana }\end{array}$ \\
\hline
\end{tabular}

NRT: Núcleo de Reubicación el Tesoro, NTT: Núcleo de Reubicación el Turpial, NLE: Núcleo de Reubicación la Esperanza, GAC: Núcleo de Reubicación la Cosmopolitana, PEM: Parque Ecozoo Merecure; Nr: No responde. Fuente: El estudio.

Por otro lado, el NR la Cosmopolitana nunca cambio sus parentales lo cual trajo como consecuencia consanguinidad dando como resultado dificultades en la 
reproducción y degeneraciones. En la Figura 7 se puede observar un pequeño agujero que no se sabe cuál es su finalidad.
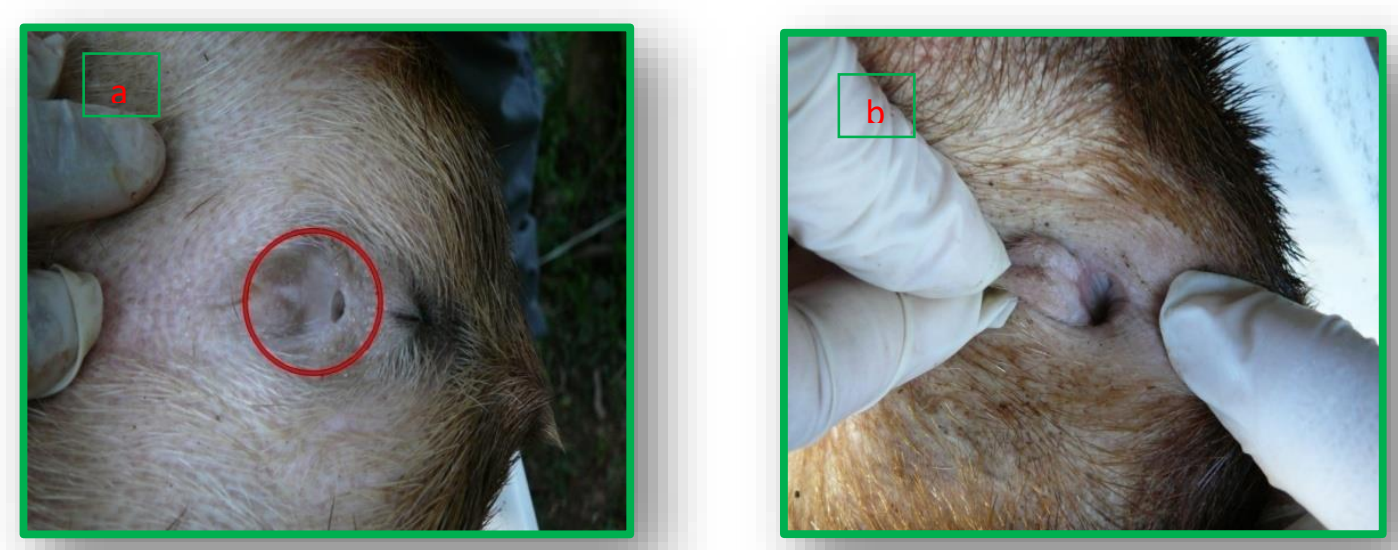

Figura 7. a. Hembra con degeneración y b. Hembra sana.

Fotografía: Tinjacá, (2007)

En el NR la Esperanza la natalidad es mayor que la mortalidad y la fecundidad además es alta, se encuentra en crecimiento. Esto indica que la población está creciendo rápidamente. De igual manera, en el NR la Cosmopolitana natalidad también es mayor que la mortalidad, lo que indica que la población se mantiene en crecimiento, el problema es la consaguinidad entre los ejemplares. Mientras que, en el NR el Tesoro la fecundidad es baja y se encuentra en decrecimiento, por tanto la población se encuentra en decremento, por lo tanto la población presenta esta tendencia y puede terminarse debido al bajo número de individuos que maneja. Por otro lado, en el NR el Turpial no se pudo analizar debido a su reciente inauguración. Finalmente en el Parque Ecozoo Merecure la población se encuentra en crecimiento debido a su amplitud en el encierro.

Gestación. Asumiendo que las hembras preñadas cuentan con el máximo de gestación indicado por Rengifo (1996) de 145 a 155 días, obteniendo un tiempo promedio de 150 días, pero a través de las entrevistas se pudo ver que todos los establecimientos las hembras preñadas tienen un tiempo inferior de gestación a 116 días, teniendo en cuenta que la gestación se afecta por la malnutrición que inhibe la fertilidad de hembras jóvenes y la productividad de hembras adultas. 
Épocas de nacimiento. En la zona tropical la ovulación, gestación y nacimientos ocurren durante todo el año, aunque dependiendo de las condiciones ambientales del encierro, las mayores frecuencias se dan en épocas determinadas. Los picos de nacimientos y la longevidad del periodo (generalmente largos) dependen de las condiciones ambientales del lugar. Los nacimientos de la población en cautiverio muestran una tendencia a la estacionalidad con un mayor porcentaje de Diciembre a Enero (70\% aproximadamente) (Tabla 3).

\section{EVALUACIÓN DE LOS ENCIERROS DE LOS NÚCLEOS DE REUBICACIÓN}

Evaluación de los encierros. Para la evaluación de los encierros se recurrió al índice de calidad de hábitat (HSI = hábitat suitability index) (Gysel \& Lyon 1980). Este índice es usado principalmente para la evaluación de hábitat en vida silvestre, pero se adaptó para evaluar los encierros de las lapas en cautiverio en los diferentes establecimientos visitados, a la vez también se tomaron en cuenta las 5 libertades propuestas por Farm Animal Welfare (1993), en donde los animales deben contar con unos estándares mínimos para su bienestar. Se establecieron cinco rangos: $1=$ Malo: elementos antrópicos que causen alto estrés como carreteras, edificaciones, objetos que causen alto ruido entre otros. $2=$ Aceptable: animales en encierros colindantes. $3=$ Regular: elementos naturales, como prado, bosques y quebradas. 4= Bueno: cumple en más de un $90 \%$ de los requerimientos del entorno natural para la lapa. 5= Excelente: cumple con el 100\% de los requerimientos del entorno natural para la lapa. Los criterios expuestos facilitaron la evaluación de los predios visitados, estos son sumados para sacar un total, n máximo 40 . Si la sumatoria pasa de la mitad de 40 es bueno. No obstante cabe anotar que unos ítems se subdividieron como es el caso de la vecindad. A partir de estos rangos se analizaron las variables como lo refleja la Tabla 5.

\section{Índice de calidad de hábitat (HSI = hábitat suitability index)}

Área del encierro. Es el área en $\mathrm{m}^{2}$ donde se encuentran los animales en cautiverio. Entre mayor es el área, mejor es para los individuos y menor la probabilidad de presentar accidentes por estrés. 
Densidad de individuos en el encierro. Es la cantidad de individuos por $\mathrm{m}^{2}$ en cada encierro evaluado. Entre menor es la densidad, mejor es para los individuos, siendo mayor el espacio neto y evitando hacinamiento. Para el cálculo de la densidad se usa el área neta del encierro, sin cuerpos de agua, ya que su presencia en grandes extensiones disminuye el terreno real que utilizan los individuos. La menor densidad obtendrá el máximo valor.

Refugio artificial. Cuando no se tiene buena cobertura climática, es necesario que exista algún refugio para que los animales se protejan del clima. En esta variable se calificaron tres sub-variables: área, volumen y material. Entre mayor es el volumen y el área por individuo, mayor valor tienen. La máxima valoración la obtienen la mayor área y volumen por individuo encontrado en campo y la mínima será sin refugio.

Área de manejo. Para la manipulación de individuos en cautiverio es necesario contar con un área de manejo que permita el aislamiento del individuo para facilitar su restricción. Si el encierro cuenta con área de manejo, obtiene una máxima calificación, si no, obtiene la mínima.

Manga de acceso. La manga de acceso permite el ingreso al encierro sin correr el riesgo de que algún individuo escape. Es un elemento básico para el manejo de individuos en cautiverio. La presencia de manga de acceso da una máxima calificación y su ausencia la mínima.

Ancho de la puerta. El ancho de las puertas en el encierro tiene que ser mínimo de $1.5 \mathrm{~m}$, para permitir un fácil ingreso de un individuo bajo restricción química ó física. El mayor ancho de puerta tendrá una máxima calificación, y el menor la mínima. Cuando exista más de una puerta en una sección, se tiene en cuenta el mayor valor.

Enmallado. En esta variable se calificaron tres sub-variables: altura de la malla, distancia entre los postes y material del enmallado. 
Vecindad. Los alrededores del encierro afecta directamente el bienestar de los individuos en cautiverio. Los diferentes elementos que colindan con los encierros fueron calificados según el grado de estrés que pueden producir a los individuos.

Tabla 5. Evaluación de encierros de los diferentes establecimientos visitados.

\begin{tabular}{|c|c|c|c|c|c|c|c|c|c|}
\hline Predio & $\begin{array}{c}\text { Área } \\
\text { del } \\
\text { encierro }\end{array}$ & $\begin{array}{c}\text { Densidad } \\
\text { animales } \\
\text { por } \\
\text { encierro }\end{array}$ & $\begin{array}{l}\text { Refugio } \\
\text { artificial }\end{array}$ & $\begin{array}{c}\text { Área } \\
\text { de } \\
\text { manejo }\end{array}$ & $\begin{array}{c}\text { Manga } \\
\text { de } \\
\text { acceso }\end{array}$ & $\begin{array}{c}\text { Ancho } \\
\text { de la } \\
\text { puerta }\end{array}$ & $\begin{array}{l}\text { Enma- } \\
\text { Ilado }\end{array}$ & $\begin{array}{l}\text { Vecin- } \\
\text { dad }\end{array}$ & Total \\
\hline NRT & 5 & 5 & 2 & 1 & 1 & 5 & 5 & 2 & 26 \\
\hline NRTu & 4 & 4 & 5 & 1 & 1 & 5 & 4 & 4 & 28 \\
\hline NRE & 3 & 3 & 2 & 1 & 1 & 3 & 4 & 4 & 21 \\
\hline${ }^{*} \mathrm{NRC}$ & $\begin{array}{l}3 \\
3\end{array}$ & $\begin{array}{l}2 \\
3\end{array}$ & $\begin{array}{l}4 \\
4\end{array}$ & $\begin{array}{l}1 \\
1\end{array}$ & $\begin{array}{l}1 \\
1\end{array}$ & $\begin{array}{l}5 \\
5\end{array}$ & $\begin{array}{l}5 \\
5\end{array}$ & $\begin{array}{l}3 \\
3\end{array}$ & $\begin{array}{l}24 \\
26\end{array}$ \\
\hline PEM & 5 & 5 & 2 & 1 & 3 & 5 & 5 & 5 & 31 \\
\hline
\end{tabular}

NRT: Núcleo de Reubicación el Tesoro, NRTu: Núcleo de Reubicación el Turpial, NRE: Núcleo de Reubicación la Esperanza, *NRC: Núcleo de Reubicación la Cosmopolitana (dos encierros), PEM: Parque Ecozoo Merecure.

\section{ANÁLISIS DEL ENCIERRO EX SITU}

El componente hábitat corresponde al encierro en donde se encuentran los animales, cuando se habla de fauna en cautiverio, también son los recursos y las condiciones presentes en un área que produce su ocupación (obligatoria en cautiverio), incluyendo supervivencia y reproducción, en otras palabras, es la suma de los recursos específicos que son necesarios para que la lapa viva de manera más o menos de manera adecuadamente (Hall et al., 1997).

El componente hábitat afecta directamente la población en cautiverio, ya que la sobrevivencia, la productividad y el bienestar de un organismo dependen de su ambiente (Ojasti, 2000), y en este caso, los animales no pueden hacer una escogencia de sitio según su preferencia de hábitat. Como consecuencia, la evaluación de los encierros puede vislumbrar la condición general de la población. La calidad de hábitat se refiere a la habilidad del ambiente para dar las condiciones apropiadas para los individuos. Ésta podría ser considerada como una variable continua que posee valores bajos, medios y altos, basada en recursos 
disponibles para la sobrevivencia, reproducción y la persistencia de las poblaciones (Hall et al., 1997).

La evaluación de los encierros se realizó según los objetivos de mantenimiento en cautiverio de la especie en los establecimientos visitados. Las calificaciones obtenidas reflejan qué tanto se están cubriendo los requerimientos de hábitat de los individuos en cautiverio, para el mantenimiento ex situ de lapa. Los encierros del Turpial y el Ecozoo son los que tienen mayores HSI debido al gran tamaño que ostentan y a la biomasa, por las condiciones generales, como el piso, arbustos y árboles en el interior del encierro (para Merecure). Por esta misma razón tienen buena valoración. El encierro el Tesoro no tiene buena calificación, debido a que es un encierro pequeño donde los animales se alimentan y se dificulta su manejo. Las densidades que se manejan son bajas y se cuenta con varios encierros de gran tamaño. En adición, los objetivos de tenencia de los animales son los mismos: conservación y producción. En comparación, los encierros del Tesoro su $\mathrm{HSI}$ es relativamente bajo, lo cual se explica por su tamaño reducido, en donde los animales son exhibidos y por lo tanto presentan estrés constante.

Merecure obtuvo el mayor HSI debido a que el encierro posee una adecuada cobertura arbórea y arbustiva, además de tener la mejor calificación; para compartir hábitat con otras especies se trasladan los animales de un encierro a otro. Por otro lado el Turpial tiene buena calificación por el número de animales (4), por lo tanto disponen de un mayor espacio, evitando que se presenten laceraciones. La Esperanza posee una calificación regular debido al número de animales para un encierro tan pequeño; el suelo y el refugio artificial no llenan las expectativas. La Cosmopolitana no cuenta con un piso adecuado que colabore con el bienestar de los animales, pero el tipo de enmallado es el ideal para todos los núcleos de reubicación pues evita escape de éstos.

\section{ANÁLISIS DE LOS NÚCLES DE REUBICACIÓN}

En los cuatro NR y en el parque el principal problema detectado fueron los refugios, porque no cuentan con un área de manejo, manga de acceso y cerca de 
encierro, en algunos casos cuando la tiene el área del encierro es reducida, como es el caso de la Cosmopolitana y el parque. En el Tesoro, se encuentran cabañas vacacionales, donde colocan música y hacen ruido constante, similar situación se observa en la Comopolitana, donde el encierro de lapas lo visitan muchas personas, que aunque no entran, le tiran cosas o mueven los refugios para poder observar los animales.

Todas estas situaciones detectadas en los cinco predios producen estrés a los animales y peleas entre ellos por el mejor refugio, dificultando su manejo y posibles pérdidas de individuos por fugas, lo cual ocasiona laceraciones y golpes en los animales por intentar escapar, que puede traer enfermedades por agentes patógenos, alterando la reproducción y alimentación

En general, los establecimientos mostraron grandes diferencias en cuanto al mantenimiento de los animales, la experiencia en el manejo de la especie y su objetivo. Los objetivos del mantenimiento en cautiverio de ésta especie varían entre los establecimientos visitados. Los NR el Tesoro y la Cosmopolitana tienen como objetivos la exhibición (recreación), al igual que el Parque Ecozoo Merecure, solo que éste también lo enfoca hacia la conservación e investigación de la especie y hacia la educación; mientras que el NR La Esperanza tiene como objetivos la conservación, reproducción (comercialización) y educación, además de hacerlo por gusto hacia los animales; el NR El Turpial se enfoca en la investigación y en el repoblamiento.

En cuanto al tiempo de experiencia con la especie en cautiverio, el establecimiento con mayor tiempo con la especie es el NR la Esperanza (1997), le siguen NR la Cosmopolitana (1998), Parque Ecozoo Merecure (2001), NR el Tesoro (2003), y por último el Turpial (2007).

El encierro de dos hectáreas de parque Ecozoo Merecure, obtuvó el mayor índice de calidad de hábitat $(\mathrm{HSI}=$ hábitat suitability index) y las 5 libertades propuestas por Farm Animal Welfare, de 40 puntos posibles su calificación fue de 31, le siguió en su orden, el encierro de $35 \mathrm{~m}^{2}$ del NR el Turpial con 28 puntos; en los demás 
encierros las evaluaciones fueron por debajo de 26 , aunque todos cumplen con unos requerimientos mínimos.

\section{IDENTIFICACIÓN Y ALIMENTACIÓN}

Identificación. Se registraron 48 individuos de lapa en los predios visitados, 29 fueron marcados, 19 de los cuales tenían doble marcaje, y 19 que no se pudieron identificar. Las técnicas utilizadas para el marcaje de individuos varían según la necesidad u objetivos del establecimiento. Del total de animales registrados, 10 se han marcado mediante la técnica de muescas en las orejas, 19 con tatuaje de tinta ó en frío y 33 con agujero en la oreja. Actualmente, todos los individuos están marcados, pero cuando se hizo la visita solo 29 de los 48 individuos lo estaban. De los 19 individuos con sin marca, cuatro pertenecían al RN el Turpial y 15 al Parque Ecozoo Merecure; los restantes estaban con marca sencilla en el RN la Esperanza, pero no era visible para identificarlos.

El marcaje es indispensable para el seguimiento de individuos, se encontró que en sólo dos predios de los visitados se lleva un adecuado registro de la información: en el NR el Turpial y el Ecozoo Merecure se llevan registro de los animales en historias clínicas. En los demás no se encontró ningún tipo de registro o información acerca de las lapas, por tanto ésta depende completamente de la memoria de las personas que los cuidan.

Manejo alimenticio. La alimentación de las lapas debe cubrir requerimientos nutricionales de fibra, proteínas, energía, vitaminas y minerales, lo cual se logra mediante una dieta balanceada para mantener el buen estado de salud, contribuyendo de esta manera al éxito de la reproducción en cautiverio, permitiendo mayor proporción de partos. Se puede observar que la cantidad de alimento diario suministrado por individuo en cada establecimiento, es al tanteo excepto en el Ecozoo Merecure, pero en ninguno de los núcleos se maneja dietas diferentes para machos, hembras, hembras gestantes, lactantes y juveniles.

La dieta entre los predios varía en tipo de alimentos y cantidad, y depende de la época de la cosecha; se observó que en todos se suministra: yuca, plátano, maíz, 
soya, palma de moriche, cacao, carambolo, guayaba, maraco, aguacate, patilla, caña de azúcar, pan de año, arracacha, matarratón, y mamey que solo lo suministran en el NR la Cosmopolitana. En el Ecozoo Merecure, los alimentos se ofrecen picados, lavados y pesados en los comederos de 4 a 5 de la tarde, en los demás, los pican, si son de gran tamaño y se los suministran también en la tarde.

\section{MANEJO VETERINARIO}

El manejo veterinario es necesario en cautiverio, ya que los animales en estas condiciones tienden a enfermar más que los de vida libre, debido a una disminución en las defensas producida por el estrés viviendo en hacinamiento, porque se pierden comodidades que se tienen en vida libre. Para disminuir estos riesgos se utiliza la medicina preventiva, la cual es indispensable para el cuidado adecuado e incluye procedimientos de cuarentena, exámenes de rutina, pruebas paraclínicas y programas de vacunación si la especie lo requiere. En los establecimientos visitados la medicina preventiva se reduce a la desparasitación, lo cual es básico, ya que los animales silvestres en cautiverio son vulnerables a numerosas infecciones, las cuales son transmitidas generalmente por los domésticos.

Parte del manejo veterinario que debe hacerse a las lapas consiste en su manipulación mediante captura, contención y/o anestesia, más aun si están destinadas para investigación científica y su manejo pueda ser algo rutinario. La habilidad para llevar a cabo procedimientos con seguridad, tanto para el animal como para los manejadores, es importante para el desarrollo de cualquier proyecto de investigación. Sin embargo, es indispensable que exista una razón valedera para manipular directamente un animal. En los establecimientos visitados la restricción se realiza para atender las urgencias médicas, desparasitar, trasladar los individuos e investigar. Las lapas son los mamíferos con la mayor predisposición al síndrome denominado "miopatía post-captura", por tanto la restricción física debe ser realizada previa a la restricción química. Las dosis de tranquilizantes y anestésicos utilizados en cada establecimiento fueron diferentes pues no todos respondieron a la misma cantidad por ejemplo en el NR el Turpial la 
dosis fue más alta comparada con la Cosmopolitana puesto que los primeros animales se están manipulando seguidamente, mientras que los últimos era la primera vez que se les suministraba. Los fármacos utilizados fueron Ketamina, Xilacina y Atropina que son los agentes anestésicos empleados con mayor frecuencia en la práctica veterinaria en Colombia.

\section{REINTRODUCCIÓN}

Debido a que los predios visitados no cumplen con los requisitos para liberación de fauna, los individuos que se encuentran actualmente en cautiverio no son aptos para programas de reintroducción o repoblación.

Se entiende por repoblación fáunica ó reintroducción todo acto que conduzca a la reimplantación de poblaciones de especies, subespecies, razas o variedades nativas de fauna silvestre en áreas en las cuales existen o existieron, siempre y cuando las causas que originaron su extinción hayan desaparecido y/o estén controladas. La repoblación fáunica tiene por objeto promover la recuperación y/o el incremento de las poblaciones nativas de fauna silvestre y restaurar el equilibrio de los ecosistemas de los cuales las especies fáunicas forman o formaban parte (Decreto 1608 de 1978, Decreto "Por el cual se reglamenta el Código de Recursos Naturales Renovables y de Protección al Medio Ambiente, la Ley 99 de 1993 y la ley 611 de 2000 en materia de fauna silvestre").

Según la ley colombiana, para este efecto se deberá elaborar y/o autorizar un plan de repoblación que deberá contemplar las fases de evaluación, liberación y monitoreo. Durante la fase de evaluación se debe comprobar que la especie objeto de repoblación existe o existió en el área receptora, se debe verificar que las causas que produjeron la reducción poblacional ya no existen o se encuentran controladas, se deben estudiar los requerimientos biológicos y de hábitat de la especie, definir la capacidad de carga del área o ecosistema objeto de repoblación, y se debe contar con la procedencia e identificación taxonómica de los especímenes, así como sus características biológicas, genéticas y sanitarias. 
Además, se debe contar con un análisis de riesgo sobre las poblaciones naturales y ecosistemas receptores.

Durante la fase de liberación, se debe implementar las medidas profilácticas de los individuos a liberar, realizar una valoración biológica y sanitaria de los mismos y determinar el área o ecosistema receptor.

\section{RECOMENDACIONES PARA LOS ENCIERROS}

NR el Tesoro. Como es difícil hacer un nuevo encierro se recomienda sacar a los animales del subterráneo, hacer refugios artificiales y trasladar a las otras especies que hay en el encierro (chigüiro y morroco patiamarillo). También se le puede agregar al piso cascarilla $u$ otro sustrato para evitar laceraciones. Por otro lado que tenga asistencia técnica por lo menos dos veces al año, además que se manejen registros productivos. De tal forma que su distribución quedaría como lo plantea la Figura 8.

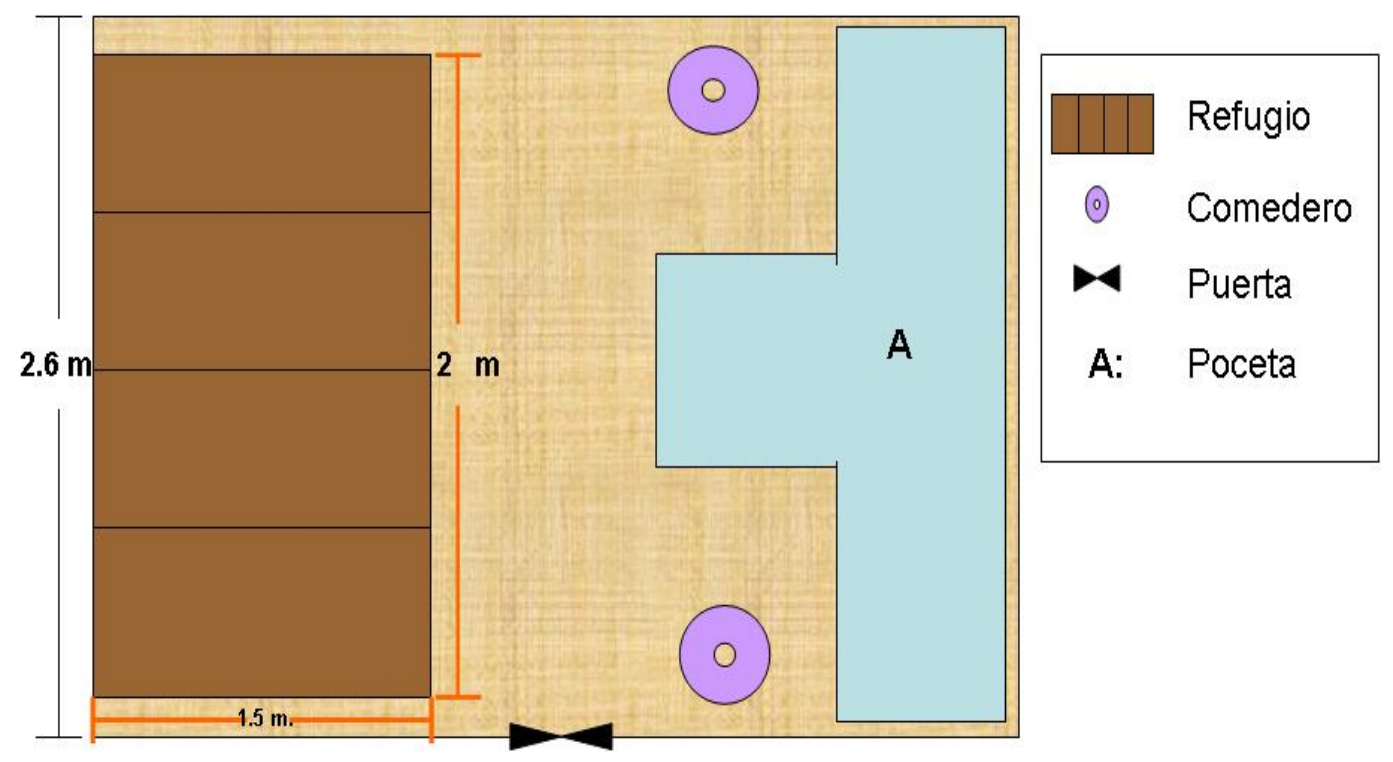

Figura 8. Diseño recomendado al encierro del núcleo de reubicación el Tesoro

NR la Esperanza. La recomendación para éste establecimiento es reducir la biomasa, además agregarle cascarilla al suelo, arreglar los refugios artificiales y cambiar la puerta ya que presenta alto riesgo de fuga. En adición, implementar 
registros, asistencia técnica y quitar las esquinas ya que no son recomendables (Figura 9).
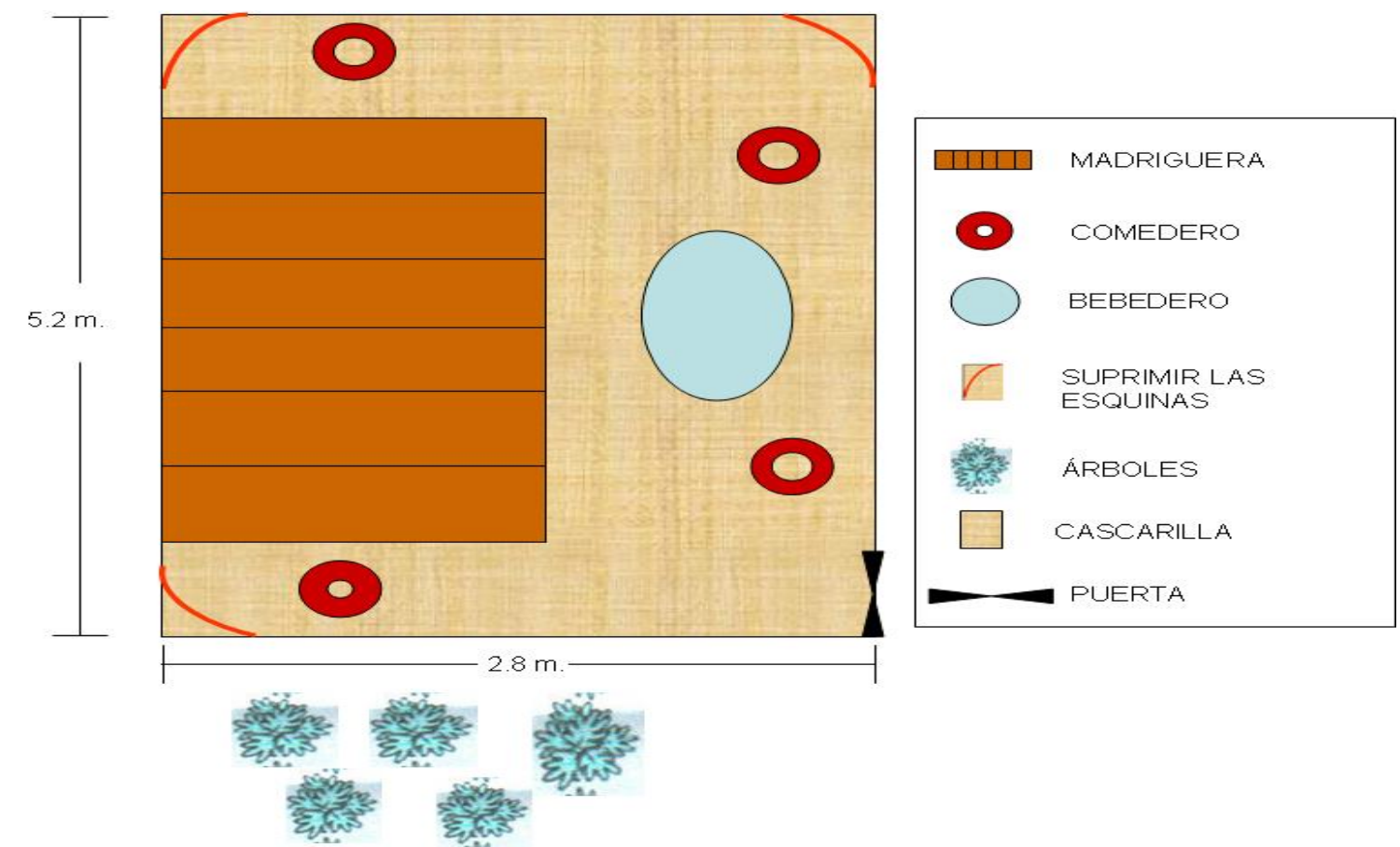

Figura 9. Diseño para organizar el encierro del núcleo de reubicación la Esperanza.

NR el Turpial. En este es necesario hacer una división para apartar las hembras preñadas pues el macho tiende a golpearlas provocándoles heridas fuertes, también se recomienda quitar las esquinas del encierro, puede ser con la misma malla u otros materiales según la conveniencia del propietario (Figura 10).

NR la Cosmopolitana: Tiene el encierro ideal lo único faltante es agregar cascarilla en el piso, lo cual facilitaría el manejo. Además implementar registros productivos y asistencia técnica, también se recomienda mejorar la limpieza de los nidos.

Parque Ecozoo Merecure: En el parque sería ideal implementar un método de captura de los animales y mejorar los refugios artificiales. 


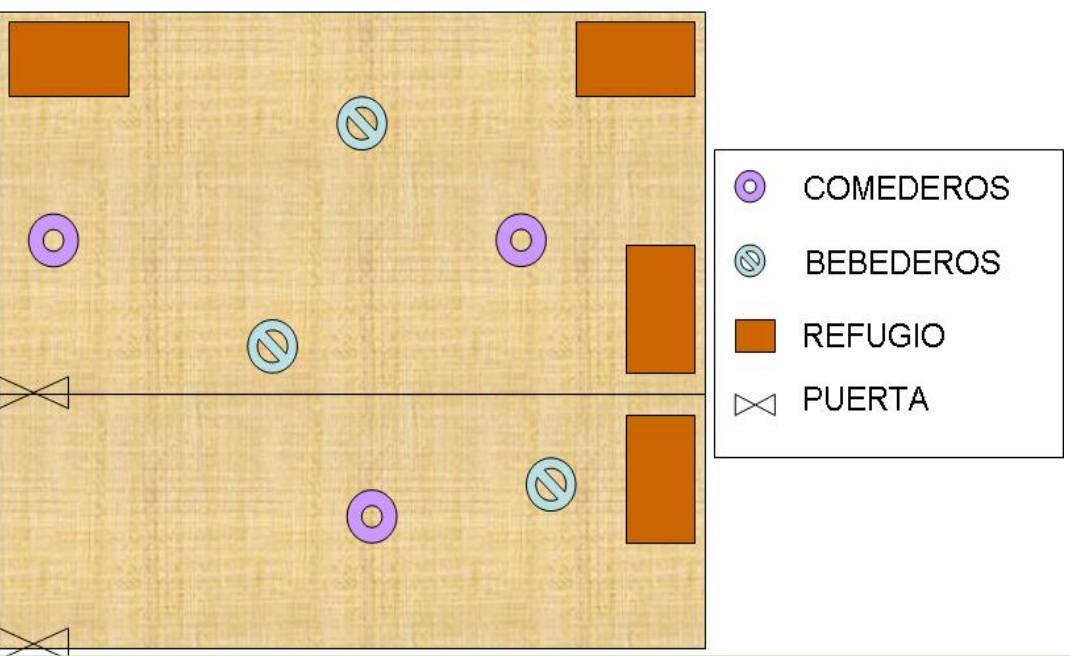

Figura 10. Diseño para mejorar el encierro del núcleo de reubicación el Turpial.

\section{RECOMENDACIONES DE MANEJO DE LOS INDIVIDUOS}

Se recomienda a los establecimientos marcar todos los individuos de lapa que tienen en cautiverio, marcarlos con perforaciones en las orejas para permitir su identificación a distancia y evitar la restricción innecesaria; llevar un correcto registro de los individuos con datos de: número de registro, número de marcaje, especie, nombre común, sexo, fecha de nacimiento o adquisición, edad, fecha de marcaje.

Aunque es necesario implementar planes de manejo veterinario de los individuos, es importante mencionar que la restricción se debe realizar sólo en casos específicos, como última opción.

Los predios visitados son aptos para la zoocría, pero deben obtener la licencia ambiental respectiva, según su objetivo. Para esto, deben seguir la normatividad vigente. Además se recomienda para el NR la Esperanza mejorar dieta, instalaciones y hábitat de las lapas, para el manejo de los individuos y de esta forma implementar programas de atención veterinaria y reproductiva para una máxima productividad. En el NR el Tesoro, cuyo propósito es recreación requiere mejorar su infraestructura para facilitar el trabajo, además se debe realizar manejo reproductivo para evitar el incremento de individuos amansando a neonatos. En el 
NR la Cosmopolitana, cuyo objetivo es educación se debe cambiar los parentales por la alta consanguinidad; por otro lado se debe mejorar el piso puesto que es en concreto lo cual trae como consecuencia lesión en las extremidades. El Parque Ecozoo Merecure que es un zoológico sus objetivos se restringen a exhibición, investigación y educación. Se observa que se está mejorando el hábitat ex situ, para lo cual se siguen recomendaciones específicas. Es de anotar que el parque cuenta con encierro adecuado, tiene el mejor manejo veterinario y alimenticio comparado con los demás predios. Sin embargo, se recomienda fabricar un refugio con materiales naturales (madera, hojas de palma) para generar mayor bienestar a los individuos.

Referente a las investigaciones que se realizan en el NR el Turpial, se ha estudiado la química sanguínea en lapas, además se vienen evaluando las experiencias en el manejo, lo cual se demuestra en los documentos de restricción, transporte y situaciones con animales, urgencias y escapes, desarrollados por los profesionales del establecimiento.

\section{CONCLUSIONES}

La mayoría de establecimientos visitados no están aportando a la conservación ex situ, puesto que no exponen actividades de investigación; estos deben proveer estrategias y métodos para el manejo de poblaciones pequeñas, de forma que se conserve la diversidad biológica a nivel ex situ y se aumente el soporte a esfuerzos de conservación in situ de estas poblaciones.

De los cinco establecimientos visitados en ninguno se registra o reportó parásitos externos, ni internos, las muertes que se han presentado han sido de vejez o por causas ajenas; por lo tanto se cree que estos animales son resistentes a los parásitos tanto externos como internos, lo que los hace animales aptos para la zoocría.

La fecundidad ha aumentado a través del tiempo, lo que implica un incremento en la tasa de natalidad y por tanto en la densidad de la población en cautiverio, teniendo en cuenta la baja mortalidad de las clases juvenil a mayor de ocho años. 
Los individuos en cautiverio según las observaciones en los cinco predios no son aptos para programas de reintroducción, pues estos ya han sufrido un proceso de amansamiento, lo que indica que al momento de devolverlo a su medio natural podrían ser presa fácil de depredadores.

En todos los predios visitados se hace necesario la implementación de planes de bioseguridad, para mejorar la calidad de vida de los animales y por ende de las personas que están en constante contacto con ellos.

En los predios visitados se requieren programas e instalaciones para el manejo adecuado de las lapas las cuales son hiperestésicas, para acostúmbralas a la presencia de las personas, de esta manera se puede reducir el nerviosismo y el estrés. Además en la aplicación de anestesia se debe tener en cuenta la varianza individual, pues algunos animales adquieren resistencia debido a que se manejan seguidamente.

Se recomienda promover el uso sostenible de la lapa teniendo en cuenta sus características favorables para una zoocría productiva y lo permisible para la gente en su aprovechamiento, para así asegurar su preservación, con el beneficio que la región de los Llanos Orientales puede ser el foco de mercadeo, para ofrecer los productos provenientes de la zoocría de lapa.

\section{REFERENCIAS BIBLIOGRÁFICAS}

1. Allen, A. W. Habitat suitability index models: Marten. U.S.D.I. Fish and Wildlife Service. WS/OBS-82/10.11. 9 pp. 1982.

2. Álvarez, O., O. Salazar. Hematología y química sanguínea del venado cala blanca (Odocoileus virginianus) en cautiverio. Trabajo de grado Medicina Veterinaria. Facultad de Medicina Veterinaria y Zootecnia. Universidad Nacional de Colombia. Bogotá. 2003.

3. Arévalo E. Manual de campo para el monitoreo de mamíferos terrestres en áreas de conservación. Asociación de conservacionistas de Monteverde, Año 2001.

4. Bramble W. C., Byrnes W. R. Evaluation of the wildlife habitat values of rights of way. Journal of wildlife management 43 (3): 642-649. 1979.

5. Castro J. J. Estudio del tinajo o borugo en cautiverio, p 3-4. 1996.

6. Condori C. Elaboración de textos para alfabetización en quechua como estrategia para mejorar el aprendizaje de la lectura y escritura en el cetha "Ildefonso de las muñecas", Cochabamba, Bolivia. 2006. 
7. Cox G. W. Conservation biology. Concepts and applications. $2^{\text {nd }}$ ed. McGraw Hill. USA. Fowler, M. 1986. Zoo and wild animal medicine. p 942-952. WB Saunders Company. USA. 1997.

8. Ezcurra E., Gallina S. Biology and population dynamics of white tailed deer in northwestern México. Chapter IV. En: Ffolliot P. F. \& S. Gallina. Deer biology, hábitat requirements, and management in western North America. Instituto de Ecología, México. 1981.

9. Gómez C. M. Nuestros bosques, Consulta cartográfica sobre Medio Ambiente y ecosistemas estratégicos. Ministerio del Medio Ambiente, 1996.

10. Gómez C. M. Estrategia nacional para la prevención y el control del tráfico ilegal de especies silvestres. Ministerio del Medio Ambiente, 2002.

11. Gysel L. W., Lyon L. J. Análisis y evaluación de hábitat. En: Rodríguez Tarrés. Manual de técnicas de gestión de vida silvestre. Wildlife Society, Maryland. 1980.

12. GTZ/FUNDECO/IE. Estrategia regional de biodiversidad para los países del trópico andino. Convenio de cooperación técnica no reembolsable ATN/JF5887-RG.Documento temático del III taller regional de conservación ex situ. La Paz, Bolivia. 2001. Disponible En: http://www.comunidadandina.org/

13. Hall, L. S., Krausman, P. R., Morrison M. L. The habitat concept and a plea for standard terminology. Wildlife Society Bulletin, 25: 173-182. 1997.

14. Hernández O. M., Peña R. J. Elaboración de un manual divulgativo sobre la determinación del número adecuado de hembras por macho en la producción de huevo fértil de codorniz (Coturnix coturnix japonica) como instrumento didáctico para mejorar la productividad coturnicola en la zona rural de Villavicencio, Unillanos, Programa de Licenciatura en Producción Agropecuaria, 2006.

15. Hungerford C. R., Burke M. D., Ffolliot P. F. Biology and population dynamics of mule deer in South Western United States. Chapter V. En: Ffolliot P. F. \& S. Gallina. Deer biology, habitat requirements, and management in western North America. Instituto de Ecología, México. 1981.

16. Hoyos Z. E. Normas Icontec, presentación de tesis, trabajos de grado, y otros trabajos de investigación, 2007.

17. ICONTEC. Compendio tesis y otros trabajos de grado, Normas técnicas colombianas sobre documentación. 2007.

18. Instituto Alexander Von Humboldt. Proyecto "Estado de las poblaciones cautivas del género Ateles en Colombia: studbook". 2005. Disponible En: www.humboldt.org.co/chmcolombia/servicios/jsp/redes/primates/proyectos

19. Internacional Species Information System. 2004. Disponible En: http://www.isis.org

20. Miller A., Schwartz K., Rea I. Primer taller de registro y manejo de datos de animales de zoológico. Buenos Aires, Argentina. 2001. Disponible En: http://zcog.org/zcog\%20frames/Taller\%20ISISBuenos\%20Aires\%2001.pdf

21. Montes R.C. Rasgos alimenticios, reproductivos y potencial productivo del tepezcuintle (Agouti paca). Tropicultura, 15: 147-150. 1997.

22. Ojasti J. Manejo de fauna silvestre neotropical. Instituto de zoología tropical de la universidad central de Venezuela, 2000. 
23. Queirolo D., Vieira E., Emmons L., Samudio R. Cuniculus paca. 2008. En: IUCN 2010. IUCN Red List of Threatened Species. Version 2010.1. Consultado 16 de marzo de 2010.

24. Redford K. H., Robinson J. G. Usos comerciales y de subsistencia de la vida silvestre en América Latina. En: Robinson J. G., K. H. Redford y J. E. Rabinovich (eds.) Uso y conservación de la vida silvestre neotropical. Fondo de Cultura Económica. México D. F. 1997.

25. Rengifo M. Crianza familiar del majaz o paca (Agouti paca) en la Amazonía. En: Perú. 1996.

26. Restrepo P. J., Díaz A. H. Manual educativo sobre el manejo y zoocría de la especie zaino de collar blanco Pecari tajacu (Linnaeus, 1758), con fines de conservación y aprovechamiento sostenible de fauna silvestre, en el núcleo de reubicación San Carlos de Guarda y en el Bioparque los Ocarros. 2007.

27. Sisson S., Grossman J. D. Anatomía comparada de los animales domésticos; $4^{a}$ ed. p 30, 1996.

28. Smythe; Brown de G. O. La domesticación y cría de la paca (Agouti paca). Guía de Conservación No. 26. FAO. 1995.

29. Trujillo G. A. Curso de zoocría, 2006.

30. UICN. Recomendaciones del V Congreso Mundial de Parques de la UICN". Durban (Sudáfrica). 94 p. 2003. Disponible En: www.uicn.org.

31. Ullrey D. E., Youatt W. G., Johnson H. E., Fay L. D., Schoepke B. L., Magee W. T., Keahey K. K. Calcium requirements of weaned white-tailed deer fawns. Journal of Wildlife Management, 27 (3): 187-194. 1973.

32. Verme, L. J., Ullrey D. E. Physiology and nutrition. pp. 91-118. En: Halls L. K. White tailed deer: ecology and management. Satckpole books. USA. 1984.

33.Zapata O. F. Guía para el decomiso de especies y productos de fauna silvestre. p 7-9 y 20-21. 2006.

34.Zapata O. F. Manual para los núcleos de reubicación de fauna silvestre. p 913. 2006. 